Neurosurg Focus 25 (2):E3, 2008

\title{
Clinical feasibility of minimally invasive cervical laminoplasty
}

\author{
David M. Benglis JR., M.D., James D. Guest, M.D., Ph.D., And Michael Y. Wang, M.D. \\ Department of Neurosurgery, Miller School of Medicine, University of Miami, Florida
}

\begin{abstract}
Minimally invasive approaches to the cervical spine for lateral disc herniation or foraminal stenosis have recently been described. Lower rates of blood loss, decreased narcotic dependence, and less tissue destruction as well as shorter hospital stays are all advantages of utilizing these techniques. These observations can also be realized with a minimal access approach to cervical laminoplasty. Multiple levels of the cervical spine can be treated from a posterior approach with the potential to decrease the incidences of postoperative axial neck pain and kyphotic deformity. In this report the authors present a concise history of the open laminoplasty technique, provide data from previous cadaveric studies (6 cases) along with recent clinical experience for minimally invasive laminoplasty, and describe the advantages and challenges of this novel procedure. (DOI: 10.3171/FOC/2008/25/8/E3)
\end{abstract}

\section{KEY WORDS - cervical laminoplasty - cervical spine - cervical spondylotic myelopathy • minimally invasive spine surgery}

$\mathrm{O}$ PEN-DOOR cervical expansile laminoplasty was first described in 1978 by Hirabayashi ${ }^{9}$ and in Japan has since become an accepted form of surgical management for the treatment of ossification of the posterior longitudinal ligament. ${ }^{11}$ Other groups have demonstrated the efficacy of this technique in patients with multilevel cervical spondylotic myelopathy., ${ }^{6,10,14,16,28,32} \mathrm{Al}-$ though various modifications of the open laminoplasty exist, the goals of the procedure are to increase the space within the spinal canal and to relieve neural compression while maintaining a skeletal and ligamentous dorsal arch to prevent the development of epidural scarring and kyphotic deformity. ${ }^{33}$

Advocates of the laminoplasty procedure claim that it may help to preserve motion, reduce the incidence of adjacent segment degeneration, maintain important extensor muscle insertion points, and lead to a decreased incidence of complications encountered with traditional laminectomies such as segmental instability, kyphosis, perineural adhesions, and late neurological deterioration. ${ }^{4,5,8,15,17-19,27,34}$ Compared with anterior approaches, laminoplasty is more efficient for decompressing multiple spinal levels (4-6) and does not carry the attendant risks of dysphagia and dysphonia, which are associated with anterior neck dissections. Because laminoplasty addresses 4-6 levels, as compared with 1-3 levels in most anterior approaches, even moderately stenosed segments can be treated with limited additional morbidity.,29

Nevertheless, posterior approaches to the cervical spine are associated with a finite risk of long-standing or permanent neck and shoulder pain. In some studies, this has been found to be as high as $25-40 \%$ one year following surgery. ${ }^{12,13,20}$ Although the origin of pain in the immediate postoperative period appears to be due to subperiosteal dissection and soft tissue retraction, the cause of long-standing neck discomfort is less well understood. It has been postulated that facet joint trauma from either drilling or abnormal biomechanics contributes to these symptoms in patients undergoing laminoplasty; however, soft tissue trauma is likely to be a contributor to this very troublesome sequela of laminoplasty. For this reason, a minimal access approach to cervical laminoplasty may be desirable.

Minimally invasive posterior approaches to the cervical spine have recently been developed for the treatment of foraminal stenosis and lateral disc herniations., ${ }^{3,22}$ Building on initial experiences with tubular dilator retractors used for lumbar microdiscectomy, several groups have begun applying this technique for cervical foraminotomy. In a landmark paper, Adamson ${ }^{1}$ reviewed data from a series of 100 patients treated in this manner. He reported that $97 \%$ of the patients experienced good or excellent results after treatment, validating the safety and efficacy of the procedure. In their study of 25 patients Fessler and colleagues ${ }^{7}$ demonstrated lower rates of blood loss, reduced narcotic requirements, and rapid postoperative recoveries when compared with open surgical controls.

As experience with the use of tubular dilator retractors has grown, the spectrum of pathologies treated via a minimal access approach has expanded to include lumbar fusions, posterior cervical fusions, and tumor resection. ${ }^{21}$, 24,30,31 Nevertheless, long segment decompression of cervical stenosis has remained elusive, due in part to the number 


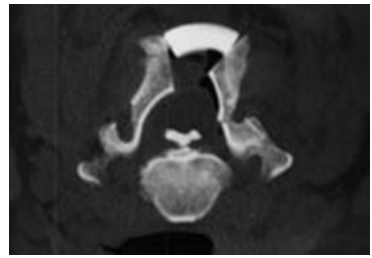

FIG. 1. Postoperative CT scan at C-2 demonstrating the axial double-door laminoplasty with hydroxyapatite spacer (muscle preservation technique). Note that the muscular attachments are preserved on the spinous process of C-2. Reprinted with permission from Shiraishi T, Yato Y: Neurosurgical Focus 12 (1):1-3, 2002.

of segments that typically require treatment as well as the inherent hazard associated with surgery to decompress the severely compressed spinal cord.

\section{Minimally Invasive Cervical Laminoplasty}

We have explored the feasibility of performing a multilevel laminoplasty via an exposure that could be achieved with a tubular retractor system in cadavers. ${ }^{29} \mathrm{~A}$ minimally invasive approach to cervical laminoplasty would preserve important muscular attachments (the semispinalis cervicis and multifidus muscles), prevent muscle atrophy, and potentially reduce the incidence of postoperative axial neck pain and kyphotic deformity. Several Japanese investigators have explored this concept of preserving muscle attachments while utilizing open operative techniques. They have developed the "skip laminectomy" and "double-door laminoplasty" (Fig. 1) as well as laminoplasty methods through access windows between critical muscular attachments. ${ }^{25}$, ${ }^{26,35}$ Although no definitive studies have demonstrated the superiority of these techniques over traditional open methods, several concepts have emerged from clinical experience. Perhaps the most important idea is the maintenance of musculoligamentous attachments to the axis and vertebra prominens. The spinous processes at these anchor points at the top and bottom of the cervical lordotic curvature provide lever arms and actuators important in the dynamic "tension band," which confers stability to the cervical spine. In addition, observed rates of postoperative infection, when compared with open techniques, may be lower given the decrease in tissue devitalization. ${ }^{23,32}$

\section{Cadaveric Experience with Minimally Invasive Laminoplasty}

We have demonstrated the feasibility of performing minimally invasive laminoplasty at multiple levels in human cadavers at the University of Miami. ${ }^{29}$ Our study involved 6 adult specimens requiring an average time of 1.5-2 hours per procedure. Cadavers with thicker, more muscular necks required a longer 5-cm tubular retractor, and the placement of the rib allograft was more difficult in these specimens. Average spinal canal areas changed from $2.15 \pm 0.24 \mathrm{~cm}^{2}$ (mean \pm standard deviation) preoperatively to $3.09 \pm 0.13$ $\mathrm{cm}^{2}$ postoperatively, whereas the sagittal diameter increased from $1.24 \pm 0.098$ to $1.71 \pm 0.11 \mathrm{~cm}$ at the C-5 level. These changes in both the spinal canal area $(\mathrm{p}=$ $0.0004)$ and sagittal diameter $(\mathrm{p}=0.0001)$ were statistically significant.
D. M. Benglis Jr., J. D. Guest, and M. Y. Wang

\section{Surgical Technique of Minimally \\ Invasive Open-Door Laminoplasty}

Building on experiences in the laboratory, this surgical procedure was applied in a limited number of patients at the University of Southern California. The procedure was performed in patients with critical cervical stenosis who had presented with acute central cord syndrome (Video 1). Patients were positioned prone with the head supported by a Mayfield skull clamp, and the neck was maintained in neutral alignment. Electrophysiological monitoring with somatosensory evoked potentials, motor evoked potentials, and electromyography was used throughout, as was the operating microscope.

VIDEO 1. Clip showing the intraoperative technique for minimally invasive cervical laminoplasty for the treatment of multisegmental cervical stenosis.

Real Player: http://mfile.akamai.com/21489/rm/ digitalwbc.download.akamai.com/21492/real.digitalsource-naregional/foc08-75Video1.ram

Windows Media:http://mfile.akamai.com/21490/wmv/ digitalwbc.download.akamai.com/21492/wm.digitalsourcena-regional/foc08-75Video1.asx

Two-centimeter-long incisions were made bilaterally (at C-4 and C-6) $2 \mathrm{~cm}$ lateral to the midline (total of 4 small incisions). A series of tubular dilator retractors were then introduced with a final diameter of $14 \mathrm{~mm}$ and directed medially to allow docking onto the junction of the laminae and lateral masses. The laminae and facet joints were observed through the ports, and obstructing soft tissue was removed using monopolar cautery and pituitary rongeurs.

The tubular retractor could be manipulated rostrally or caudally in the sagittal plane to expose 1 or 2 segments above the level of the incision. At this point an operating microscope was brought in and facilitated lighting and visualization of these structures. The hinge side of the laminoplasty was then drilled, leaving the inner cortex intact. A continuous gutter was thus created from the cranial to the caudal extents of decompression by using a high-speed bur with a "matchstick" style tip. A small laminotomy was made at the rostral and caudal ends on this side. Attention was then turned to the open side where a similar gutter was drilled along the lamina-facet junction. On this side, however, drilling was completed through both the inner and outer cortex with extension of the laminotomy to connect the rostral and caudal laminotomies from the other side. Along the open-door side of the laminoplasty, the ligamentum flavum was removed using a 1-mm Kerrison rongeur and then en-bloc elevation of the lamina was accomplished. Resorbable polylactic acid spacers packed with demineralized bone matrix or bone autograft measuring $10 \mathrm{~mm}$ high were placed at C-4 and C- 6 to maintain this dorsal elevation..$^{29}$ There exists a certain amount of tissue compliance that allows opening of the lamina over 5 levels. At the most cranial and caudal ends, however, expansion of the lamina may not be as pronounced when compared with its appearance in open approaches.

Key points in performing this procedure include the following: 1) Fluoroscopic confirmation of the levels treated on the right versus the left side of the patient must be 
obtained to ensure proper preparation of the dorsal arch for en-bloc lifting. 2) The proper docking site onto the laminafacet junction must be confirmed to avoid drilling the gutters too laterally. 3) A slightly medially directed trajectory must be maintained for drilling of the gutters. 4) Careful elevation of the laminae under tension must be achieved to allow the natural tension of the ligaments to maintain spacer placement. 5) Meticulous hemostasis must be obtained with the use of powdered gelatin formulations. 6) Avoid using the Steinman pin for tube placement as it may inadvertently enter the spinal canal or anterior neck. 7) Release the table-mounted retractor attachment when lifting the laminae so that the tube does not prevent proper dorsal movement of the laminae.

This technique remains challenging and the typical surgical procedure time is more than twice the duration of open laminoplasty procedures. Nonetheless, it is likely that the development of specific instruments to allow safer drilling and laminar elevation could make this technique more feasible for wide application. Large studies with proper controls and objective patient-driven outcome assessments are necessary to validate the ability of minimal access techniques to reduce postoperative neck pain, discomfort, and stiffness.

\section{Conclusions}

The standard laminoplasty technique is a technically straightforward method of achieving long-segment spinal canal decompression. Complications associated with the technique are low; however, a considerable number of patients experience lingering neck or interscapular pain after the procedure. It is thought that this pain is due to the removal of muscle and tendinous attachments from the lower cervical vertebrae. Our goal was to develop a less invasive technique that could provide spinal cord decompression but leave the midline muscular and tendinous attachments intact. Minimally invasive cervical laminoplasty, although technically challenging, may become more feasible in the future after the development of instruments specific for this approach.

\section{Disclaimer}

The authors do not report any conflict of interest concerning the materials or methods used in this study or the findings specified in this paper.

\section{References}

1. Adamson TE: Microendoscopic posterior cervical laminoforaminotomy for unilateral radiculopathy: results of a new technique in 100 cases. J Neurosurg 95 (1 Suppl):51-57, 2001

2. Beutler WJ, Sweeney CA, Connolly PJ: Recurrent laryngeal nerve injury with anterior cervical spine surgery. Spine 26:1337-1342, 2001

3. Burke T, Caputy A: Microendoscopic posterior cervical foraminotomy: a cadaveric model and clinical application for cervical radiculopathy. J Neurosurg 93 (1 Suppl):126-129, 2000

4. Cybulski GR, D’Angelo CM: Neurological deterioration after laminectomy for spondylotic cervical myeloradiculopathy: the putative role of spinal cord ischaemia. J Neurol Neurosurg Psychiatry 51:717-718, 1988

5. Dai L, Ni B, Yuan W, Jia L: Radiculopathy after laminectomy for cervical compression myelopathy. J Bone Joint Surg Br 80: 846-849, 1998

6. Deutsch H, Mummaneni PV, Rodts GE, Haid RW: Posterior cervical laminoplasty using a new plating system: technical note. J Spinal Disord Tech 17:317-320, 2004

7. Fessler RG, Khoo L: Minimally invasive cervical microendoscopic foraminotomy: an initial clinical experience. Neurosurgery 51 (5 Suppl):37-45, 2002

8. Herkowitz HN: A comparison of anterior cervical fusion, cervical laminectomy, and cervical laminoplasty for the surgical management of multiple level spondylotic radiculopathy. Spine 13: 774-780, 1988

9. Hirabayashi K: [Expansive open-door laminoplasty for cervical spondylotic myelopathy.] Jpn J Surg 32:1159-1163, 1978 (Jpn)

10. Hirabayashi K, Satomi K: Operative procedure and results of expansive open-door laminoplasty. Spine 13:870-876, 1988

11. Hirabayashi K, Toyama K, Chiba K: Expansive laminoplasty for myelopathy in ossification of the posterior longitudinal ligament. Clin Orthop Relat Res 359:35-48, 1999

12. Hosono N, Sakaura H, Mukai Y, Yoshikawa H: The source of axial pain after cervical laminoplasty-C7 is more crucial than deep extensor muscles. Spine 32:2985-2988, 2007

13. Hosono N, Yonenobu K, Ono K: Neck and shoulder pain after laminoplasty. A noticeable complication. Spine 21:1969-1973, 1996

14. Kawakami M, Tamaki T, Iwasaki H, Yoshida M, Ando M, Yamada H: A comparative study of surgical approaches for cervical compressive myelopathy. Clin Orthop Relat Res 381:129-136, 2000

15. Kimura I, Oh-Hama M, Shingu H: Cervical myelopathy treated by canal-expansive laminoplasty. Computed tomographic and myelographic findings. J Bone Joint Surg Am 66:914-920, 1984

16. Lee TT, Manzano GR, Green BA: Modified open-door cervical expansive laminoplasty for spondylotic myelopathy: operative technique, outcome, and predictors for gait improvement. J Neurosurg 86:64-68, 1997

17. Lonstein JE: Post-laminectomy kyphosis. Clin Orthop Relat Res 128:93-100, 1977

18. Morimoto T, Ohtsuka H, Sakaki T, Kawaguchi M: Postlaminectomy cervical spinal cord compression demonstrated by dynamic magnetic resonance imaging. Case report. J Neurosurg 88:155-157, 1998

19. Mikawa Y, Shikata J, Yamamuro T: Spinal deformity and instability after multilevel cervical laminectomy. Spine 12:6-11, 1987

20. Nakama S, Nitanai K, Oohashi Y, Endo T, Hoshino Y: Cervical muscle strength after laminoplasty. J Orthop Sci 8:36-40, 2003

21. O'Toole JE, Eichholz KM, Fessler RG: Minimally invasive approaches to vertebral column and spinal cord tumors. Neurosurg Clin N Am 17:491-506, 2006

22. Roh S, Kim D, Cardoso A, Fessler R: Endoscopic foraminotomy using MED system in cadaveric specimens. Spine 25:260-264, 2000

23. Satomi K, Ogawa J, Ishii Y, Hirabayashi K: Short-term complications and long-term results of expansive open-door laminoplasty for cervical stenotic myelopathy. Spine J 1:26-30, 2001

24. Schwender JD, Holly LT, Rouben DP, Foley KT: Minimally invasive transforaminal lumbar interbody fusion (TLIF): technical feasibility and initial results. J Spinal Disord Tech 18: S1-6, 2005

25. Shiraishi T, Fukuda K, Yato Y, Nakamura M, Ikegami T: Results of skip laminectomy-minimum 2-year follow-up study compared with open-door laminoplasty. Spine 28:2667-2672, 2003

26. Shiraishi T, Yato Y: New double-door laminoplasty procedure for the axis to preserve all muscular attachments to the spinous process (technical note). Neurosurg Focus 12(1):E2, 2002

27. Sim FH, Suien HJ, Bickel W, Janes JM: Swan-neck deformity following extensive cervical laminectomy. A review of twenty-one cases. J Bone Joint Surg Am 56:564-580, 1974

28. Wang MY, Green BA: Operative nuances: open-door cervical 
D. M. Benglis Jr., J. D. Guest, and M. Y. Wang

expansile laminoplasty. Neurosurgery 54:119-124, 2004

29. Wang MY, Green BA, Coscarella E, Baskaya MK, Levi A, Guest JD: Minimally invasive cervical expansile laminoplasty: an initial cadaveric study. Neurosurgery 52:370-373, 2003

30. Wang MY, Levi AD: Minimally invasive lateral mass screw fixation in the cervical spine: initial clinical experience with long-term follow-up. Neurosurgery 58:907-912, 2006

31. Wang MY, Prusmack CJ, Green BA, Gruen JP, Levi AD: Minimally invasive lateral mass screws in the treatment of cervical facet dislocations: technical note. Neurosurgery 52:444-448, 2003

32. Wang MY, Shah S, Green BA: Clinical outcomes following cervical laminoplasty for 204 patients with cervical spondylotic myelopathy. Surg Neurol 62:487-493, 2004

33. White AA III, Panjabi MM: Biomechanical considerations in the surgical management of cervical spondylotic myelopathy. Spine 13:856-860, 1988
34. Yasuoka S, Peterson HA, MacCarty CS: Incidence of spinal column deformity after multilevel laminectomy in children and adults. J Neurosurg 57:441-445, 1982

35. Yukawa $\mathrm{Y}$, Kato F, Ito $\mathrm{K}$, Horie $\mathrm{Y}$, Hida $\mathrm{T}$, Ito Z, et al: Laminoplasty and skip laminectomy for cervical compressive myelopathy: range of motion, postoperatve neck pain, and surgical outcomes in a randomized prospective study. Spine 32:1980-1985, 2007

Manuscript submitted May 15, 2008.

Accepted May 30, 2008.

Address correspondence to: Michael Wang, M.D., Department of Neurosurgery, Miller School of Medicine, University of Miami, 1095 NW 14th Terrace, Miami, Florida 33136. email: mwang2 @ med.miami.edu. 